\title{
On Some Issues of Developing a new Public Transport Movement Scheme
}

\author{
Alexey Borovskoy ${ }^{1 *}$, Evgeny Glushchenko ${ }^{1}$, Olga Borovskaya ${ }^{1}$, and Stanislav Khodov ${ }^{1}$ \\ ${ }^{1}$ Belgorod State Technological University named after V.G. Shukhov, 46 Kostyukova str., Belgorod, \\ 308012, Russia
}

\begin{abstract}
Currently, the city is actively developing and expanding, but with this comes the problems associated with the transport network. The number of vehicles is growing, and sometimes there is no way to expand the roads. This means that it is necessary to establish a public transport movement for the convenience of residents, so that it is more convenient to travel around the city, unlike personal transport.
\end{abstract}

\section{Introduction}

Intensive development of both cities and adjacent territories due to the construction of individual housing construction projects leads to a growth in traffic of vehicles on suburban-core connections. This is due, first of all, to the lack of social facilities - schools, kindergartens, hospitals, etc., in the suburban zone, as well as to the uneven distribution of the places where labor force is applied [1]. Overlapping the general growth of motorization of the population all this leads to great problems in organizing the movement in the "peak" time. For example, the number of vehicles in 2003 was 347,283 units, and already in 2016, 642,050 units. As you can see the number of cars has increased almost 2 times, but with the length of roads the situation is slightly different. From 2003 to 2013, the figure changed from $19407 \mathrm{~km}$ to $19504 \mathrm{~km}$, after which there was a decline to $19088 \mathrm{~km}$. And only in 2016 the mark was established at $20,722.6 \mathrm{~km}$. But with the extension and the number of vehicles, the need to install new traffic lights has also increased, which was done [2].

\section{Material and methods}

So in the Belgorod agglomeration it was decided to develop a public transport system. The consequence of this was the development of a model for the organization of regular passenger transportation in the Belgorod agglomeration, which includes both financial and dispatch control systems, as well as measures to develop a new public transport scheme and the corresponding reconstruction of sections of the street-road network for it [1]. At the initial stage, it was determined that the development of a new scheme would be carried out in the geo-information system, to ensure the analysis of all available data and ongoing research. For the graphic background, Open Street Map was used as the most complete

* Corresponding author: a.e.borovskoy@gmail.com 
version of the really existing graphic representation of the transport infrastructure of the Belgorod agglomeration $[3,4]$.

\section{Results}

At the first stage, work was carried out to reconcile the existing scheme of public transport traffic, available both on the official documentation, and taking into account the most common navigation systems and analysis of the actual furnishing on the busiest stopping complexes. As a result, all inconsistencies in the official documentation were revealed, which included: the inconsistency of the names of stops and data of route passports (fig. 1), the inconsistency of some routes in navigation systems (2GIS) with real routes, and the presence of "illegal" carriers operating on unapproved official routes. Part of the research was done on-site, and the mapping of all stop points and the creation of a single registry was carried out on the basis of geodetic surveys and the formation of a single register of stop stations (fig. 2) with the formation of their passports [5]. In general, the final documents are issued in the form of a single register of stop points, graphic material (fig. 3) in NextGIS QGIS and passports of stop points [6].

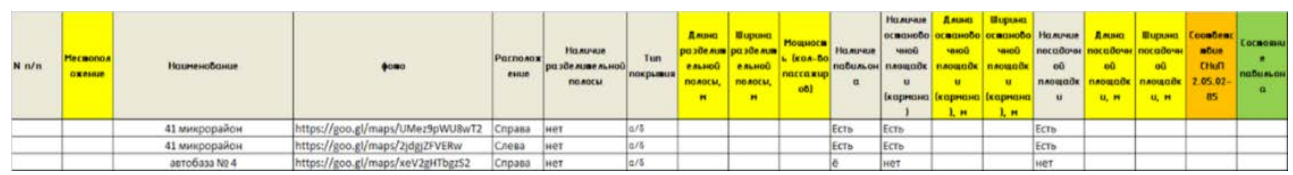

Fig. 1. Passport of the bus stop.

\begin{tabular}{l|l|}
\hline \multicolumn{1}{|c|}{ A } \\
\cline { 2 - 2 } & \multicolumn{2}{|c|}{ Наименование остановочного комплекса } \\
\hline 2 & Железнодорожный вокзал \\
\hline 3 & Железнодорожный вокзал \\
\hline 4 & Железнодорожный вокзал \\
\hline 5 & Железнодорожный вокзал \\
6 & Железнодорожный вокзал \\
\hline 7 & улица Белгородского полка \\
8 & Стоматологическая поликлиника \\
\hline 9 & Улица Николая Чумичова \\
10 & Улица Николая Чумичова \\
11 & Кинотеатр "Победа" \\
12 & улица Пушкина \\
\hline
\end{tabular}

\begin{tabular}{|c|c|c|c|c|}
\hline B & C & D & E & F \\
\hline ID & Широта & Долгота & Высота над уровнем моря Служебные пометки \\
\hline 1 & 50.59354 & 36.60536 & 127.482 & \\
\hline 2 & 50.59562 & 36.60620 & 138.244 \\
\hline 14 & 50.59354 & 36.60536 & 127.346 & \\
\hline 15 & 50.59354 & 36.60536 & 127.374 \\
\hline 16 & 50.59575 & 36.60607 & 127.419 \\
\hline 17 & 50.59677 & 36.60377 & 134.379 \\
\hline 18 & 50.59775 & 36.59669 & 133.615 \\
\hline 19 & 50.59842 & 36.59175 & 140.766 \\
\hline 20 & 50.59844 & 36.59157 & 140.988 \\
\hline 22 & 50.59933 & 36.58501 & 147.970 \\
\hline
\end{tabular}

Fig. 2. Register of bus stops.

The coordinates of the stops were recorded in the GIS in the WGS 84 co-ordinate system, for their subsequent use in a single dispatching system, and the coordinate data was obtained using geodetic survey on Trimble R3 equipment using base station data to improve accuracy [7].

At the same time, the passport of the stopping complex was created using the same technology, all dimensions and objects on it are geodetically tied, which makes it possible in the future to determine its throughput and other parameters [8].

Based on the obtained data, a map of the pedestrian accessibility of the stop points was constructed (fig. 4), based on the analysis in NextGIS QGIS, which has the following form. 


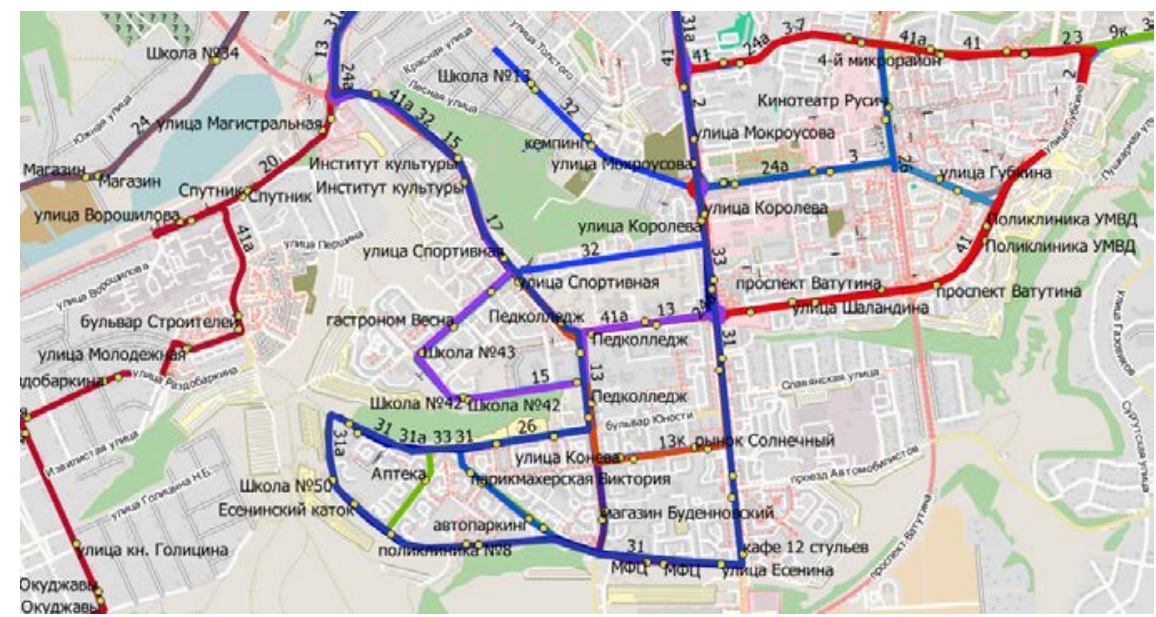

Fig. 3. Graphic display of bus stops on the route network of Belgorod agglomeration.

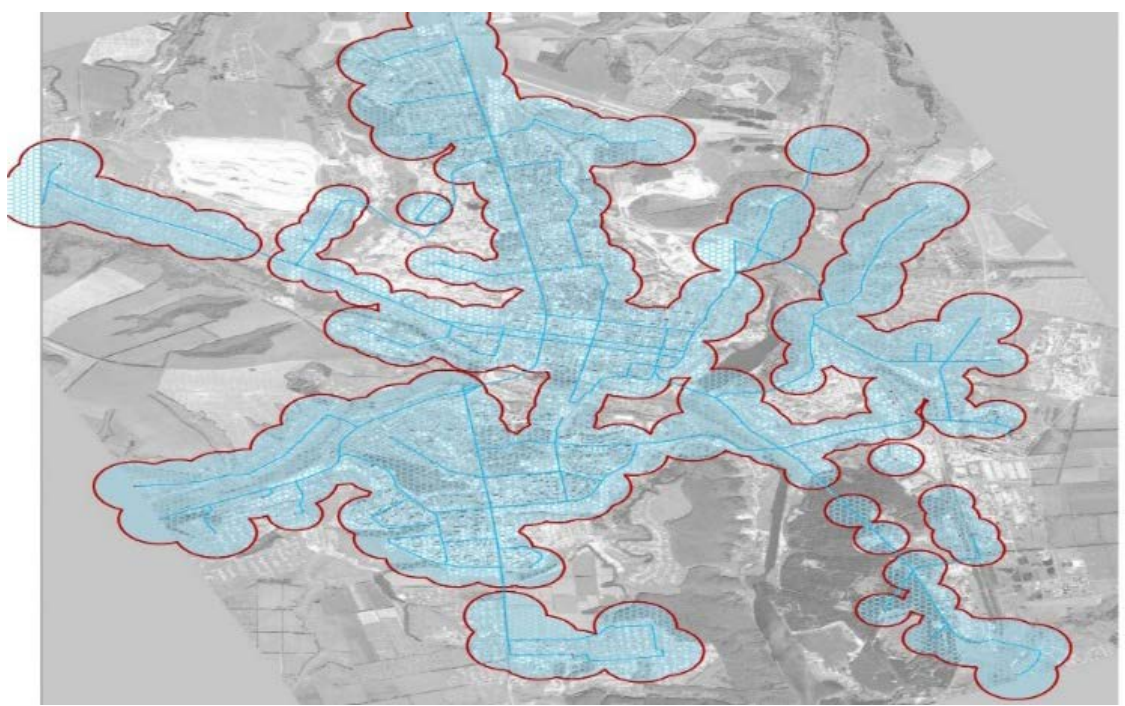

Fig. 4. Scheme of pedestrian accessibility of public transport stops of the Belgorod agglomeration.

As the analysis showed, there are zones that are not covered by the public transport system, i.e. in the system there are real zones of inaccessibility, which had to be eliminated when developing a new scheme [9]. As a result, the general scheme of the existing transport system in NextGIS QGIS is formed (fig. 5-6), taking into account all available data.

Further, data on citizens' appeals to transport departments of the city and the Belgorod region were collected and processed. This was done to identify the shortcomings of the existing system. After the end of the cameral data processing, both selective measurements of passenger flows and in-situ studies on creating a matrix of passenger correspondence were carried out [10]. For each route, forms were created with a list of corresponding stops and the number of incoming and outgoing passengers was fixed. Studies were conducted in the morning rush hour from 7-00 to 9-00 on each route. As a result, a cartogram of the passenger flow of Belgorod agglomeration was obtained, which is shown in the figure 7. 


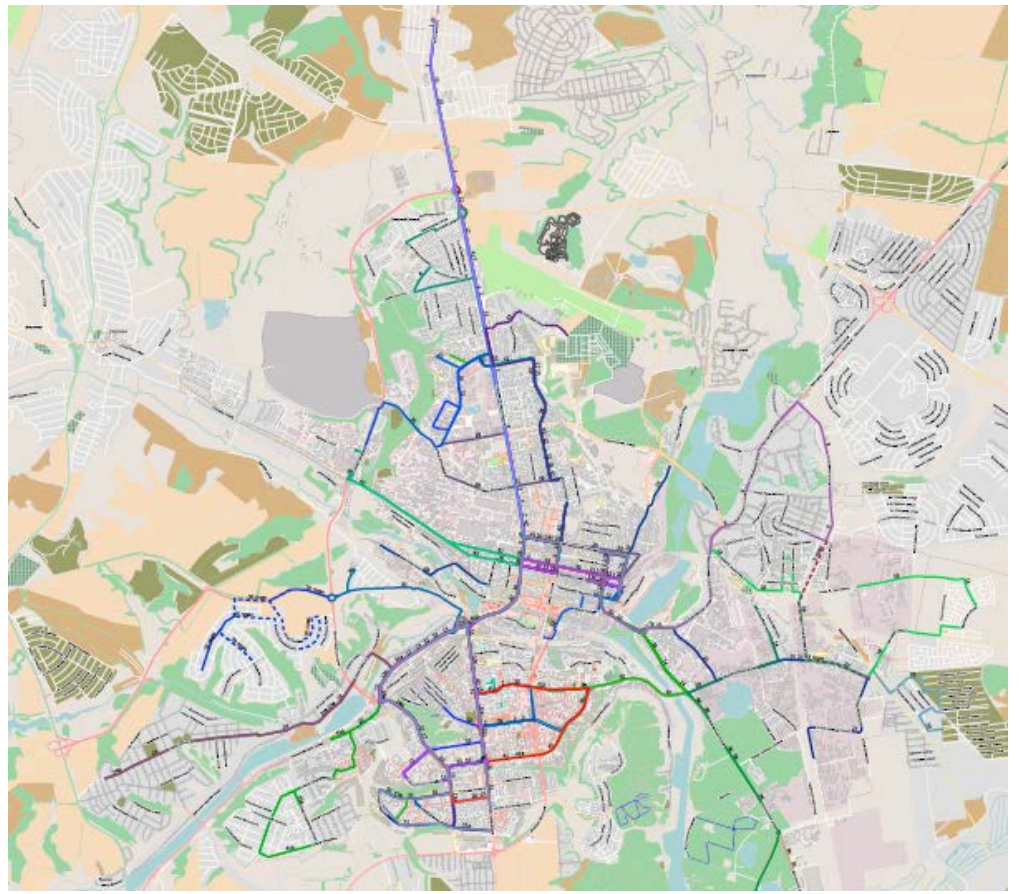

Fig. 5. General outline of existing routes.

At the same time, the scheme of "illegal" routes with the schedule of work on them is separately formed.

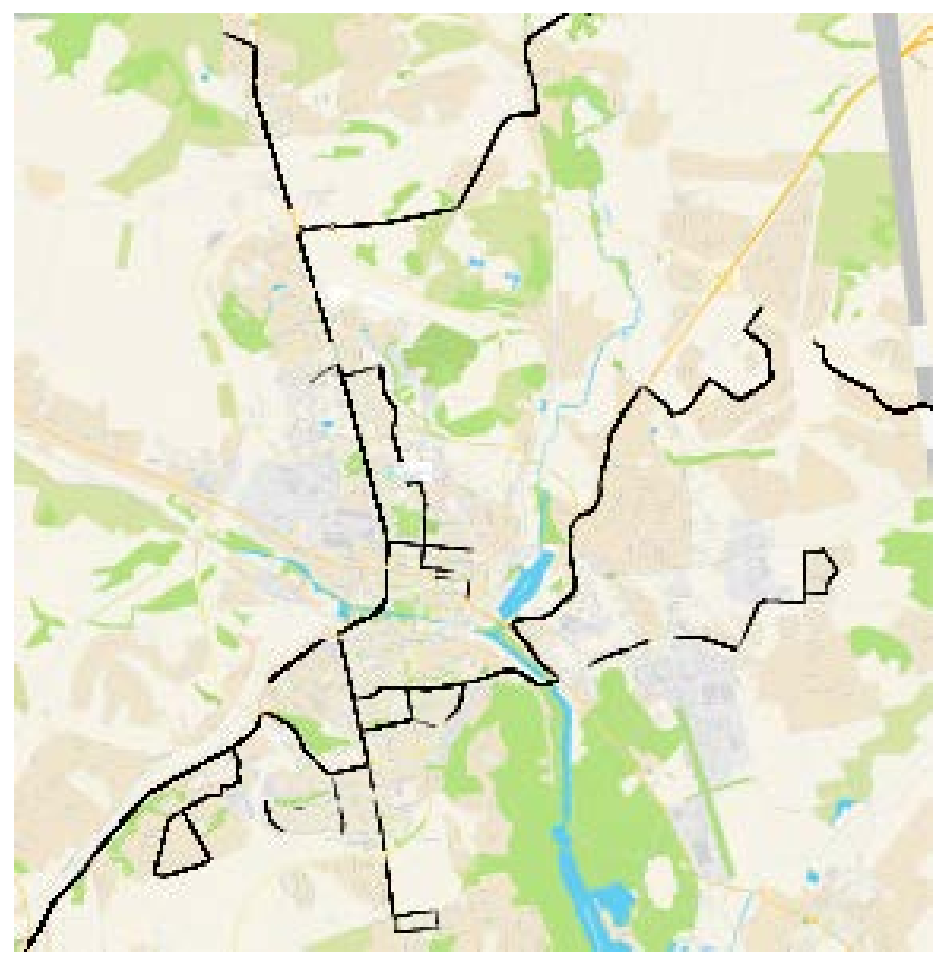

Fig. 6. Scheme of public transport on officially unregistered routes. 


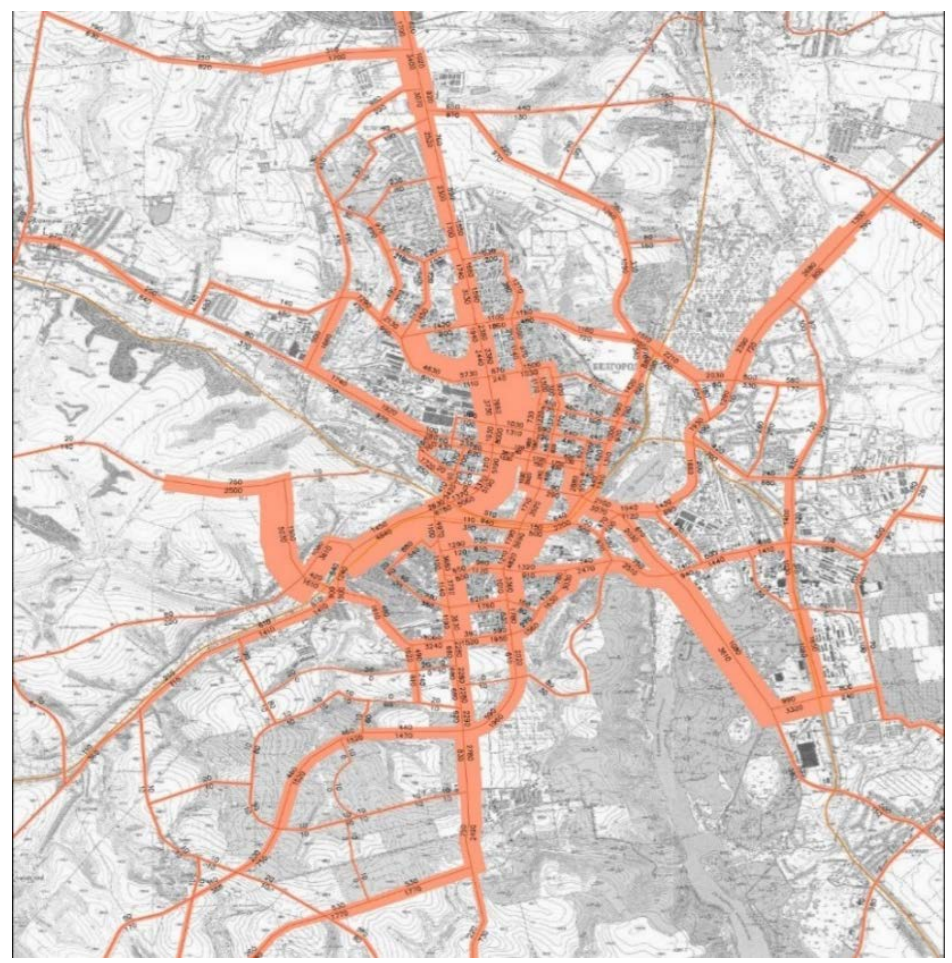

Fig. 7. Consolidated cartogram of passenger flows of Belgorod agglomeration.

\section{Discussion}

Based on the "ticket" method, a matrix of inter-set correspondence was formed (fig. 8), which made it possible to calculate the most connected areas of the city [11].

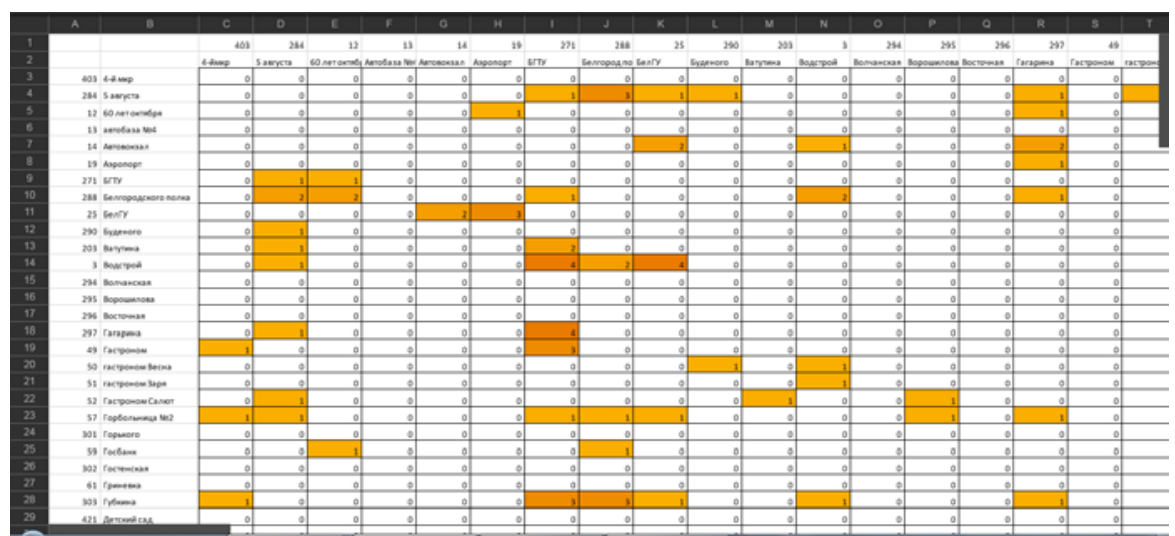

Fig. 8. The matrix of passenger traffic.

These data were analyzed and aggregated into a cartogram of passenger flows divided into transport zones. Further, the ranking of passenger traffic connections was carried out and on the basis of 1 to 10 points, both between the zones and the inter-stop points [12]. 
In more detail, this scheme was created for interconnection points. Based on the obtained data, a new scheme of public transport of Belgorod agglomeration was formed, which has the following form (fig. 9).

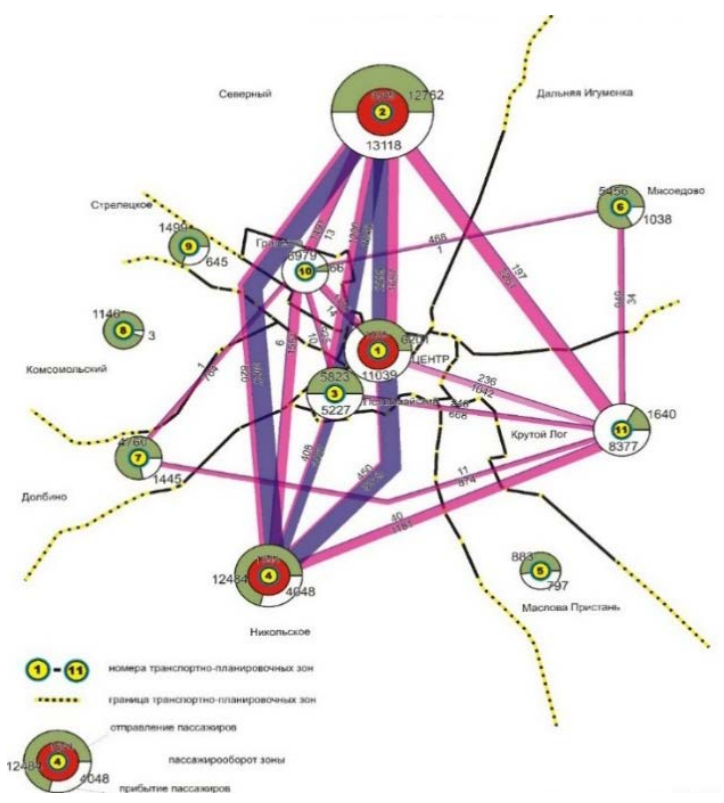

Fig. 9. Correspondence matrix for transport zones.

In more detail, this scheme was created for interconnection points. Based on the obtained data, a new scheme of public transport of Belgorod agglomeration was formed, which has the following form (fig.10).

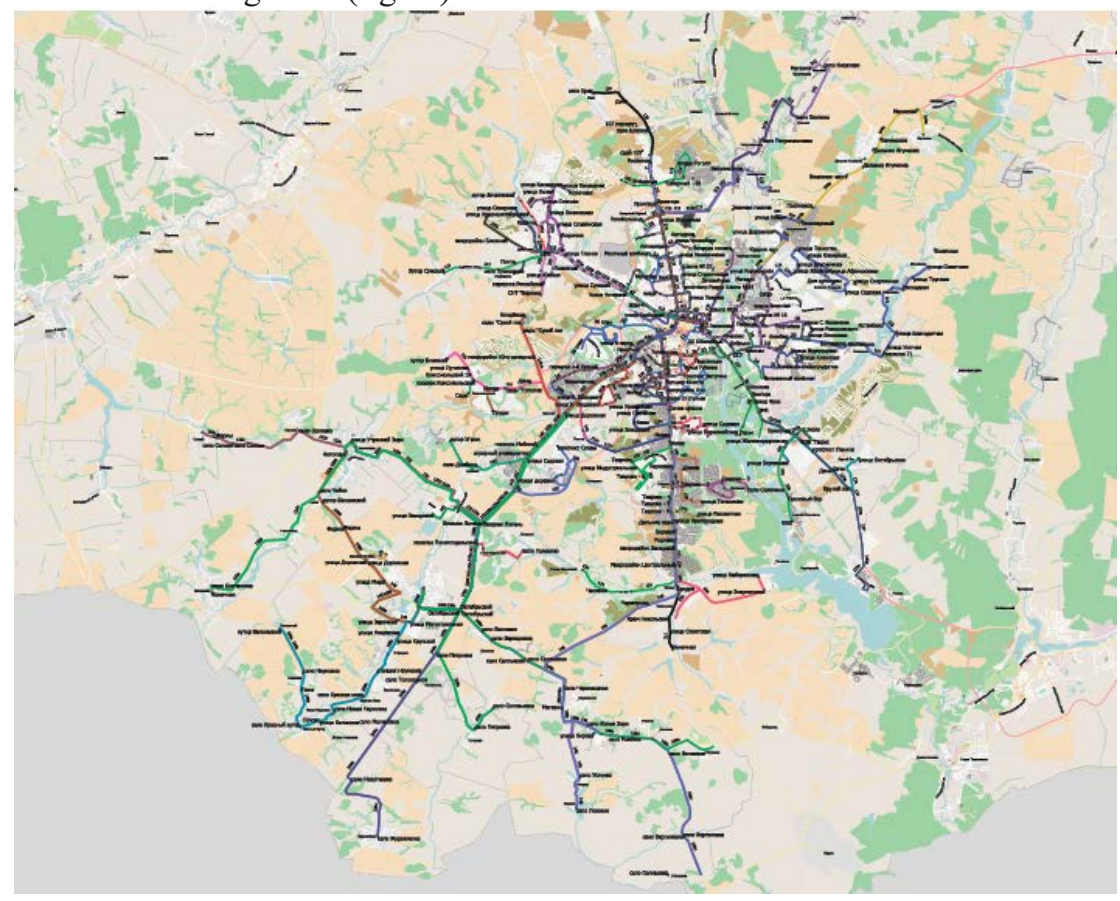

Fig. 10. New scheme of public transport of Belgorod agglomeration. 


\section{Conclusion}

Proceeding from the above, it is possible to draw conclusions:

- Correction of existing schemes of public transport is impossible without carrying out large-scale in-situ studies of passenger traffic and the characteristics of the street-road network [13].

- Before the start of work on the development of a new route network or the correction of the existing one, it is necessary to create a road graph of the surveyed area or settlement, with the creation of a complete register of stop points.

- For a correct analysis of the existing route network and the location of the stopping complexes, it is necessary to use modern GIS systems with special applications that allow estimating transport and pedestrian accessibility [14].

- Analysis of the transport and pedestrian accessibility of both the stopping complexes and the transport system itself should be carried out on the basis of the constructed graph of the roads of the road network and pedestrian paths, taking into account the step-by-step accessibility, which will allow us to identify inaccessible zones and offer solutions for the construction of new stopping complexes, and to change the pedestrian infrastructure [15].

- Such work should be carried out in a comprehensive manner, taking into account not only scientific and planning decisions, but also based on the results of wide discussion, including in the mass media.

In the future, it is planned to calculate the number of necessary rolling stock and its capacity on the basis of the speed indicators at peak time on the basis of data received from the dispatch centers of the carriers.

\section{References}

1. A.E. Borovskoy, S.I. Sokorev, I.A. Novikov, Creation of exact models of transport streams on the basis of geoinformation data. In the collection: Information technologies and innovations in transport materials of the 2nd International Scientific and Practical Conference. Under the general editorship of A.N. Novikov, pp. 10-19 (2016)

2. I.A. Novikov, A.E. Borovskoy, S.I. Sokorev, E.I. Glushchenko, Analysis of dynamic parameters of traffic flows generated by urban agglomeration objects. In the collection: Regional Scientific and Technical Conference on the results of oriented fundamental research on interdisciplinary topics, conducted by the Russian Foundation for Basic Research and the Government of the Belgorod Region, a collection of reports, pp. 245-255 (2016)

3. A.E. Gorev, K. Bettger, A.V. Prokhorov, R.R. Gizatullin, Transport modelling. 1 st edition. SPbGASU. SPb .: SPbGASU, 30, 168 p. (2015)

4. http://gis-lab.info/projects/osm-export.html, (2017)

5. V.F. Babkov, Road conditions and traffic safety: Textbook. For universities. M.: Transport, 290 p. (1993)

6. http://docs.qgis.org/2.2/ru/docs/gentle_gis_introduction/vector_attribute_data.html, (2017)

7. V.Yu. Andrianov, GIS in Transport, ArcReeview, 1 (64), pp.12-14 (2013)

8. L.B. Mirotin, Y. E. Tashbaev, V.D. Gerami, etc. Logistics: public passenger transport, Under the general. Ed. L.B. Mirotina. M .: Exam, 224 p. (2003)

9. V.V. Silyanov, The theory of traffic flows in the design of highways and traffic management. M .: Transport, 301 p. (1977) 
10. K.N. Arkatova, A.E. Borovskoy, E.I. Glushchenko, V.E. Kharuzin, Improving road safety through trajectory analysis of the movement of route vehicles. In the collection: Modern automotive materials and technologies (SAMIT-2016), a collection of articles of the VIII International Scientific and Technical Conference. Executive Editor E.V. Ageyev, pp. 13-22 (2016)

11. A.M. Lukyanov, A.E. Borovskoy, V.M. Polyakov, E.I. Yakovleva, On some issues of using navigation systems to determine the life cycle of highways. Technique and technology of transport, 1, pp. 26-31 (2016)

12. L.G. Bolshedvorskaya, Single transport system. Moscow: MSTUGA (2008)

13. Saul Wordworth. Will and sentiment: the automated road to heaven,/ Traffic Technology International. October / November 2006, pp. 54-58 (2006)

14. A.R. Bekboev, K.B. Arykbaev, Geoinformation system (GIS) is the optimization of routes and monitoring of transport. Bulletin of KSUCTA, pp. 58-61 (2013)

15. V.S. Korolyuk, N.I. Portenko, A.V. Skorokhod, A.F. Turbin, A handbook on probability theory and mathematical statistics. M .: Science, 640 p. (1985) 